\title{
Risk Factors of PTSD and Depression among Bereaved Adolescents in Selected Children's Homes in Kajiado County, Kenya
}

\author{
Journal of Medical Clinical Case Reports Research Article
}

\author{
Sheba Atieno Okumu \\ Department of Psychology and Counseling, Daystar University, Nairobi, Kenya \\ Submitted : November 9 $9^{\text {th }}, 2019$ \\ Accepted : December $5^{\text {th }}, 2019$ \\ Published : December $12^{\text {th }}, 2019$ \\ Correspondence author \\ Sheba Atieno Okumu \\ Department of Psychology and Counseling \\ Daystar University, Nairobi \\ P.O Box 242-40601 \\ BONDO \\ Nationality: Kenyan \\ Phone : +254 727805296,0770791326 \\ E-mail : shaomak2015@gmail.com
}

\begin{abstract}
According to DSM-5 criteria, risk factors can be pre-traumaic, peri-traumatic, and post-traumatic.The pre-traumatic factors are cited as temperamental, environmental, genetic and physiological. The peri-traumatic (environmental) factors are family dysfunctionality, and lack of social support, stressful environment among others. Post-traumatic factors are the those of the trauma, the greater the magnitude of trauma, the greater the likelihood of PTSD. The study was to establish the risk factors of PTSD and Depression. The study took place in 8 selected children's homes in Kajiado County, Kenya. Based on Casagrande sample size calculation, a sample size of 160 bereaved adolescents aged 12-18 years who met the inclusion criteria was sampled. A purposive sampling technique was used and data was collected using Socio demographic Questionnaires, University of California Los Angeles (UCLA) PTSD Reaction Index (Adolescents version) and Children's Depression Inventory (CDI). Data was analyzed descriptively and inferentially using IBM SPSS (version20) statistical software. The study showed that risk factors of PTSD among bereaved adolescents was gender and living with guardians. Gender is a risk factor for developing PTSD in $p=0.04$ for males and $p=0.020$ for females and living with guardians after bereavement seen at $p$ value of 0.20.The data indicated that gender and living with a guardian is a risk factor for developing PTSD and Depression among bereaved adolescents.
\end{abstract}

Keywords: Risk Factors, Post-Traumatic Stress Disorder, Depression, Bereaved, Adolescents, and Children's Homes

\section{Introduction and Background}

According to DSM-5 criteria, risk factors can be pre-traumaic, peri-traumatic, and post-traumatic.The pre-traumatic factors are cited as temperamental, environmental, genetic and physiological. The tempramental can be childhood emotional problems during the formative years and prior mental disorders. The environmental factors are family dysfunctionality, and lack of social support, stressful environment among others. The genetic and physiological factors might be certain genotype that can increase or protect risk of PTSD [1].

Post-traumatic factors are the dose of the trauma, the greater the magnitude of trauma, the greater the likelihood of PTSD. These include percieved life threat, personal injury, interpersonal violence among others [1]. The peri-traumatic factors are temperamental and enviromental. Temperamental involve negative appraisal, and improper coping skills. Enviromental factors subsequent exposure to repeated upsetting reminders,subsequent life events, and social support system predisposes the traumatized individual to develop PTSD [1].

According to Greenburg there are two strong factors which determine the development of PTSD; the first is previous mental health status of an individual while the second is the availability

and quality of social support during recovery period [2]. A study conducted among adolescence found that bereavement was likely to worsen the condition of person. Likewise, a bereaved person who lacks a social support system and living in a stressful environment is likely to develop PTSD [2]. It further explains that the intensity of PTSD depends on many factors. The factors are previous trauma exposures, pre-existing anxiety disorders, degree of controllability, predictability and perceived threat, developmental age, environment, family systems, genetic and neurobiological factors [3]. The different factors explain why individuals who are exposed to similar traumatic experiences may react differently, some exhibiting PTSD while others do not.

The bereaved adolescents can get angry if not told personally about the death of a significant other. Many cultures are noted to assume that adolescents do not experience the same emotions as adults [3]. Some cultures do not allow or encourage adolescents to talk about death by using actual words "death" or "died". Lack of expression of emotions and failure to talk about death may result to the development of PTSD hence needing an effective intervention. Adolescents ages 12-18 are seen as children and are not expected to express their feelings even when they have lost 
their significant others [4]. The factors also include stigmatization. It is noted that bereaved adolescents sometimes experience change of attitude that takes place in the society when they loose their signifant others. Previously friendly and approachable youths become negative and avoidant [5]. Adolescents either dissociate and or believe that they are responsible for the loss and could as well feel alone and isolated leading to PTSD.

DSM-5 posits that gender is a risk factor for development of PTSD and depression among adolescents. Females risk developing PTSD due to greater likelihood of exposure to traumatic events such as rape or child abuse [1]. This implies that gender is statistically a risk factor of PTSD among the bereaved adolescents. According to Macdonald, Danielson, Resnick, Sounders, \& Kilpatrick, female adolescents are more likely to develop PTSD than males as 3-15\% of girls and $1-6 \%$ of boys who were exposed to traumatic events developed PTSD [6]. This concurs with Nooner who also noted that female adolescents have been found to be at a greater risk for PTSD following traumatic exposure than males [7]. However, in an Indian study of adolescents, there was no significant gender differences . In the Indian study $8.9 \%$ of females and $10.5 \%$ of males developed PTSD [8]

AKenyan study on adolescents by Hamblen \& Erisn found out that there was gender difference of PTSD risk factors as $30 \%$ of boys while $42.3 \%$ of girls who had been exposed to trauma developed PTSD [9]. This was similar to other studies that indicated that girls were more vulnerable to PTSD than boys [10]. In bereaved adolescents, PTSD risk factors for girls was found to be higher due to various trauma including parentification and exposure to various types of child abuse [11]. A study that was conducted in China looked into the effect of Wenchuan earthquake on 512 survivors and found that age was positively correlated with PTSD symptoms because as age increased the symptoms of PTSD increased too. A study conducted among 4776 elementary school students in 8th-10th grade in Iceland found that girls had worse mental health than boys did. Further, children who lacked friends were more affected than others. This could be because younger children have greater attachment than older children.

Social support has been noted to have an impact on the individual's functioning after a traumatic event especially bereavement [12]. Lack of social support is associated with higher rates of PTSD. It is likely to be percieved by bereaved adolescents as rejection and can lead to feelings of detachment from those around [9]. Many adolescents living in children's homes lack social support which is likely to worsen their mental conditions [13]. A study among bereaved adolescents noted that individuals with better social support had significantly lower scores of PTSD. Social support can lessen the impact of bereavement of adolescents by affecting their post-traumatic cognition [14].

Alisic et al., described many risk factors for the bereaved as those who have received little support or understanding from others after their loss and those without family or friends nearby [13]. The findings observed that multiple strong supports help shorten the mourning process while those that are inhibited, compulsive, or uncomfortable with any form of emotion develop PTSD. Those that have experienced multiple recent losses or sudden, severe, unexpected loss and those with unresolved past losses are at risk. Those who had ambivalent feelings about the deceased when alive and reacted to the death with guilt are also vulnerable to PTSD [13]. Other risk factors for developing PTSD include living with a non-biological guardian, poverty and stigma [15]. A literature review of studies representing 15 studies conducted on orphaned children in sub-Saharan Africa found that poverty and living with non-biological caregivers was a risk factor to a achild or an adolescent experiencing maltreatment [15].

\section{Methods}

The study was conducted in 8 children's homes in Kajiado County, Kenya. The study enrolled 160 boys and girls aged 1218 years with a mean age of $14.27(\mathrm{SD} \pm 1.79)$. The respondents were also bereaved and living in the children's home. Another inclusion criterion was to have PTSD symptoms hence 6 respondents did not meet the inclusion criteria, while 154 did. Necessary approvals were sought and provided. Adolescents aged below 18 years provided assent to participate in the study while those aged 18 years provided informed consent prior to participating in the study. The researcher used holders of Master's degree in counseling psychology research assistants to administer the socio demographic questionnaires, UCLA Post Traumatic Stress Disorder (PTSD) Reaction Index, and Children's Depression Inventory (CDI). UCLA PTSD Reaction Index had been translated into English and Kiswahili.

UCLA PTSD Reaction Index is a standardized psychological testing instrument. It is a paper and pencil test that identifies PTSD symptoms among children and adolescents [16]. The new DSM-5 version of UCLA PTSD Reaction index for DSM-IV (Adolescence Version) is a semi structured interview tool that assesses trauma history and the full range of DSM5 PTSD diagnostic criteria among school-aged children and adolescents [16]. The reliability of UCLA PTSD Reactive index was tested in Nigeria with two samples. In both samples, it was found to be adequate with 88 and 89 reliability, which was considered excellent. In the same test the validity showed a positive correlation with PTSD. The relationship provided a strong construct validity evidence for UCLA PTSD Reaction Index [17]. Data analysis was done using Statistical Package for Social Sciences (SPSS) software version 20. Frequencies and percentages of traumatic events experienced by adolescents were calculated to establish how many adolescents had experienced traumatic events. Further, the types of traumatic events that bereaved adolescents had experienced were identified.

Children's Depression Inventory (CDI) was used to assess depression, which is a common disorder comorbid with PTSD [12]. It was a better option than any other tool because bereavement is often associated with severe depressive episode, particularly in adolescents. The tool was developed by Maria Kovacs based on Becks Depression Inventory (BDI) in 1977 [18]. It has since been repeatedly shown to be a valid screen for depressive symptoms in children and adolescents in different cultural backgrounds worldwide [19]. The tool was designed for self -rating of depressive symptoms in children and adolescents. CDI has 27 items quantifying several symptoms. The items are scored from a range of $0-2$. For each 
item the adolescent has three possible answers; 0 indicating an absence of symptoms, 1 indicating mild symptoms, and 2, definite symptoms. The total score can range from 0-54. Cut off points for CDI are 0-9 Normal, 11-26 Mild depression, 27-40 Moderate depression, 41-54 Severe depression [18]. The data was analyzed descriptively and inferentially with the help of IBM SPSS statistical software version 20 using descriptive, univariate, bivariate, multivariate and multimodal (visual communication) analysis. Descriptive statistics such as proportions were employed to establish the prevalence of PTSD and Depression among bereaved adolescents.

\section{Results}

The study had 154 respondents who gave informed consent or assent and met the inclusion criteria. Table 1 presents the frequency and percentage based on socio demographic characteristics of respondents at base line. Respondents were aged 12-18 years with a mean age of $14.27(\mathrm{SD} \pm 1.79)$. Respondents who were aged 12-14 years were $95(61.7 \%)$ while those who were aged $15-18$ years were 59 (38.3\%). This showed that there were more respondents who were aged 12 14 years as compared to those who were 15 years and above. There were 39 (25.3\%) males and 115 (74.7\%) females. This indicated that the study had more female than male respondents did. Respondents who were protestants were 70 (45.5\%), Catholics were 35 (22.7\%), SDA were 18 (11.7), Muslims were $2(1.3 \%)$ and others were $29(18.8 \%)$. This showed that a large number of respondents were protestants.

Table 1: Socio-Demographic Characteristics of Respondents at Base-line

\begin{tabular}{|l|l|l|l|l|}
\hline Variable & $\begin{array}{l}\text { Frequency } \\
\text { N=154 }\end{array}$ & $\begin{array}{l}\text { Percentage } \\
\%\end{array}$ & Mean & Std. Dev \\
\hline Age & \multicolumn{5}{|l|}{} & & \\
\hline $12-14$ & 95 & $61.7 \%$ & & \\
\hline $15-18$ & 59 & $38.3 \%$ & & \\
\hline Gender & \multicolumn{5}{|l|}{} & & \\
\hline Male & 39 & $25.3 \%$ & & \\
\hline Female & 115 & $74.7 \%$ & & \\
\hline Religion & \multicolumn{5}{|l|}{} & \\
\hline Catholics & 35 & $22.7 \%$ & & \\
\hline Protestants & 70 & $45.5 \%$ & & \\
\hline SDA & 18 & $11.7 \%$ & & \\
\hline Muslim & 2 & $1.3 \%$ & & \\
\hline Others & 29 & $18.8 \%$ & & \\
\hline Academic Performance & & $6.5 \%$ & & \\
\hline Poor & 10 & $22.7 \%$ & & \\
\hline $\begin{array}{l}\text { Below } \\
\text { average }\end{array}$ & 35 & $39.0 \%$ & & \\
\hline Average & 60 & $18.2 \%$ & & \\
\hline $\begin{array}{l}\text { Above } \\
\text { average }\end{array}$ & 28 & & & \\
\hline
\end{tabular}

\begin{tabular}{|c|c|c|}
\hline Excellent & 18 & $11.7 \%$ \\
\hline Exemplary & 3 & $1.9 \%$ \\
\hline \multicolumn{3}{|c|}{ Family Residence } \\
\hline Urban & 42 & $27.3 \%$ \\
\hline Rural & 51 & $33.1 \%$ \\
\hline Semi-rural & 61 & $39.6 \%$ \\
\hline \multicolumn{3}{|c|}{ Family set-up } \\
\hline $\begin{array}{l}\text { Parents } \\
\text { live } \\
\text { together }\end{array}$ & 13 & $8.4 \%$ \\
\hline $\begin{array}{l}\text { Parents } \\
\text { separated/ } \\
\text { single }\end{array}$ & 40 & $26.0 \%$ \\
\hline $\begin{array}{l}\text { Live with } \\
\text { guardian/ } \\
\text { orphaned }\end{array}$ & 101 & $65.6 \%$ \\
\hline \multicolumn{3}{|c|}{ Economic Status } \\
\hline Poor & 59 & $38.3 \%$ \\
\hline $\begin{array}{l}\text { Below } \\
\text { average }\end{array}$ & 43 & $27.9 \%$ \\
\hline Average & 40 & $26.0 \%$ \\
\hline $\begin{array}{l}\text { Above } \\
\text { Average }\end{array}$ & 7 & $4.5 \%$ \\
\hline Affluent & 5 & $3.2 \%$ \\
\hline
\end{tabular}

Table 4.2 presents the distribution of inter-group socio demographic characteristics of the respondents at base-line. The findings showed that $46(29.9 \%)$ respondents in the experimental group and $49(31.8 \%)$ in the control group were aged 12-14 years. On the other hand, $32(20.8 \%)$ respondents in the experimental group and $37(17.5 \%)$ in the control group were aged 15-18 years. Chi square test showed that there was no statistically significant difference $(p=.483)$ in the respondents ages in the experimental group and control group. In regard to gender, $17(11.0 \%)$ respondents in the experimental group and $22(14.3 \%)$ in the control group were males while $61(39.6 \%)$ in the experimental group and $54(35.1 \%)$ in the control group were females. Chi square tests showed that there was no statically significant difference $(p=.308)$ in the sex of respondents in the experimental and control groups. 
Table 4.8: Risk Factors of PTSD among Bereaved Adolescents

\begin{tabular}{|c|c|c|c|c|c|c|}
\hline \multirow{2}{*}{ Participant's PTSD at Base-line } & \multirow{2}{*}{ B } & \multirow{2}{*}{ SE } & \multirow{2}{*}{ Sig. } & \multirow{2}{*}{ Exp B } & \multicolumn{2}{|c|}{ 95\% CI for EXP B } \\
\hline & & & & & Lower & Upper \\
\hline \multicolumn{7}{|l|}{ Gender } \\
\hline Male & 2.402 & 1.172 & .040 & 11.047 & 1.111 & 109.876 \\
\hline Female & 15.381 & 2.063 & .020 & & & \\
\hline \multicolumn{7}{|l|}{ Age } \\
\hline $12-14$ & -1.054 & 1.014 & .299 & .347 & .048 & 2.546 \\
\hline $15-18$ & .213 & 1.725 & .119 & & & \\
\hline \multicolumn{7}{|l|}{ Family Reside } \\
\hline Urban & -3.031 & 1.638 & .064 & .048 & .002 & 1.197 \\
\hline Rural & -.370 & 1.208 & .051 & .690 & .065 & 7.374 \\
\hline Semi-Urban & -.031 & 1.348 & .759 & .780 & .056 & 6.774 \\
\hline \multicolumn{7}{|l|}{ Family setup } \\
\hline Parents live together & 1.782 & 2.077 & .391 & 5.943 & 101 & 347.986 \\
\hline Parents separated & 1.665 & 1.344 & .215 & 5.288 & .380 & 73.656 \\
\hline Live with Guardian & -1.158 & 1.104 & .020 & 5.243 & .308 & 77.566 \\
\hline \multicolumn{7}{|l|}{ Economic status } \\
\hline Poor & 18.845 & & .997 & & .000 & \\
\hline Below Aver & 19.467 & & .997 & & .000 & \\
\hline Average & 16.372 & & .997 & & .000 & \\
\hline Above Aver & 21.739 & & .996 & & .000 & \\
\hline Affluent & 24.374 & & .994 & & .000 & 9.748 \\
\hline
\end{tabular}

Table 4.8 presents multinomial logistic regression statistics showing how socio-demographic characteristics serve as risk factors of PTSD among the bereaved adolescents who participated in the study. Both male and female gender is a risk factor to developing PTSD seen in $p=0.040$ for males and $p=0.020$ for females who had been bereaved. This implies that gender is statistically a risk factor of PTSD among the bereaved adolescents. Further living with a guardian after being bereaved is a risk factor for bereaved adolescents to develop PTSD seen in a $p$ value of .020. This data indicated that gender and living with a guardian was a risk factor for developing PTSD among bereaved adolescents.

Risk factors of PTSD among bereaved adolescents include male gender $(\mathrm{p}=0.040)$ and female gender $(\mathrm{p}=0.020)$. This finding is similar to a study conducted in Kenya among adolescents that found that there was gender difference of PTSD risk factors as $30 \%$ of boys while $42.3 \%$ of girls who had been exposed to trauma developed PTSD [9]. This finding is similar to other studies that indicated that girls were more vulnerable to PTSD than boys [10]. This could be because girls were exposed to more traumatic events as well as due to parentification and other various types of child abuse [11]. Contrary to that, a study conducted in India among adolescents found no significant gender differences between males and females as $8.9 \%$ of females and $10.5 \%$ of males developed PTSD [8].

Living with a guardian after being bereaved was also found to be a risk factor for bereaved adolescents to develop PTSD seen in a $\mathrm{p}$ value of .020. This was similar to findings of a study that found that lack of social support had an impact on the individual's functioning after a traumatic event especially bereavement [12]. Similarly, a literature review of studies representing 15 studies conducted on orphaned children in sub-Saharan Africa found that poverty and living with non-biological caregivers was a risk factor to a achild or an adolescent experiencing maltreatment [15]. Such maltreatment would lead to a child or an adolescent developing PTSD and its comorbidities. 


\section{Discussion}

Risk factors of PTSD among bereaved adolescents include male gender $(p=0.040)$ and female gender $(p=0.020)$. This finding is similar to a study conducted in Kenya among adolescents that found that there was gender difference of PTSD risk factors as $30 \%$ of boys while $42.3 \%$ of girls who had been exposed to trauma developed PTSD [9]. This finding is similar to other studies that indicated that girls were more vulnerable to PTSD than boys [10]. This could be because girls were exposed to more traumatic events as well as due to parentification and other various types of child abuse [11]. Contrary to that, a study conducted in India among adolescents found no significant gender differences between males and females as $8.9 \%$ of females and $10.5 \%$ of males developed PTSD [8].

Living with a guardian after being bereaved was also found to be a risk factor for bereaved adolescents to develop PTSD seen in a $\mathrm{p}$ value of .020 . This was similar to findings of a study that found that lack of social support had an impact on the individual's functioning after a traumatic event especially bereavement [12]. Similarly, a literature review of studies representing 15 studies conducted on orphaned children in sub-Saharan Africa found that poverty and living with non-biological caregivers was a risk factor to a achild or an adolescent experiencing maltreatment [15]. Such maltreatment would lead to a child or an adolescent developing PTSD and its comorbidities.

\section{Conclusion}

Findings showed that risk factors of PTSD among bereaved adolescents included male $(p=0.040)$ and female gender $(p=$ 0.020 ). Further living with a guardian after being bereaved was a risk factor for bereaved adolescents to develop PTSD seen in a $\mathrm{p}$ value of .020 .

\section{Recommendations}

Adolescents PTSD risk factors include low social support, comorbid psychological problems, poor family functioning, and painful thought suppression among others [20]. PTSD is also associated with emotional processing of traumatic experiences, unsuccessful completion of the mourning process, and chronic mourning processing [21-23]. Other factors include premature inhibition of the mourning processing, previous trauma exposures and pre-existing anxiety disorders Based on the results of this study, a prioritization of psychological wellbeing of bereaved adolescents in children homes must be put in place. It is recommended that the children's department to come up with policies that would protect children and adolescents from abuse especially after bereavement. They should also come up with policies that will provide timely and targeted intervention whenever an adolescent is bereaved to prevent them from developing psychological illnesses like PTSD and depression.

\section{References}

1. American Psychiatric Association (2013) Diagnostic and Statistical Manual of Mental Disorders (DSM-5TM). Washington DC.: American Psychiatric Association.

2. Greenburg N, Brooks S, Dunn R (2015) Latest developments in posttraumatic stress disorder:diagnosis and treatment. British Medical Bulletin 114: 147-155.

3. Forman-Hoffman V, Zolotor A, McKeeman J, Blanco R, Knauer S, et al. (2013) Comparative effectiveness of interventions for children exposed to nonrelational traumatic events. Pediatrics 131: 526-539.

4. Talitwala M (2011) When death strikes what next? Nairobi- Kenya: Uzima Publishing House.

5. Parkes C, Prigerson H (2013) Beravement: Studief of grief in adult life. Routledge.

6. Macdonald A, Danielson C, Resnick H, Sounders B, Kilpatrick D (2010) PTSD and comorbid disorder in a representative sample of adolescents: The risk associated with multiple exposure to potentially traumatic events. Child abuse \& Neglect 34: 773-783.

7. Nooner K, Linares L, Batinjane J, Kramer R, Silver R, et al. (2012) Factors related to posttraumatic stress disorder in adolescents. Trauma Violence Abuse 13: 1-14.

8. Ralmussen D, Karsberg S, Karstolt K, Elkit A (2013) Victimization and PTSD in an Indian youth sample from Pune City. Open journal of epidemiology 3: 12-19.

9. Hamblen J, Erisn B (2012) PTSD in children and adolescents: National center for PTSD. Journal of American Academy of Child and Adolescent Psychiatry 49: 980-988.

10. Petersen T, Elket A, Olessen J (2010) Victimization and PTSD in a Faroese youth total-population sample. Scandinavian Journal of Psychology 51: 56-62.

11. Asukari N, Tsuruta N, Saito A (2011) Pilot study on traumatic grieftreatment program for Japanese women bereaved by violent death. Journal of traumatic stress 24 : 470-473.

12. Creamer M, Burgess P, McFarlane A (2011) Post-traumatic stress disorder: Findings from Australian national survey of mental health and wellbeing. Psychological Medicine 31: $1237-1247$

13. Alisic E, Zalta A, Van Wesel F, Larsen S, Hafstad G, et al. (2014) Rates of post-traumatic stress disorder in traumaexposed children and adolescents:meta-analysis. The British Journal of Psychiatry 204: 335-340.

14. Crombach A, Elbert T (2014) Controlling offensive behavior using Narrative Exposure Therapy a randomized controlled trial of street children. Clinical Psychological Science 3: 270-282. 
15. Crombach AE (2014) The benfits of aggressive traits: A study with current and former sreet children in Burundi. Child Abuse \& Neglect 38: 1041-1050.

16. Morantz G (2013) Maltreatment experiences and associated factors prior to admission to residential care: A sample of institutionalized children and youth in Westrn Kenya. National Institute of Health 10: 778-787.

17. Steinburg A, Brymer M, Decker K, Pynoss R (2014) UCLA PTSD reaction index. Current Psychiatry Reports 6: $96-100$.

18. Milot T, Plamondon A, Ehier L, Lemelin J, Laurent D, et al. (2013) Validity of CBCL-Derived PTSD and dissociation scales: Further evevidence in a sample of neglected children and adolescents. Child Maltreatment 18: $122-128$.

19. Kovacs M (2004) Chidren's depression inventory (CDI). Toronto: Mental Health Systems Inc.

20. Khasakhala IL, Ndetei M, Mathai M, Harder V (2013) Major depressive disorder in a Kenya youth sample:relatioonship with parenting behavior and parental psychiatric disorders. Annals of General Psychiatry 12: 15.

21. Khasakhala LM (2012) The prevelence of depressive symptoms among adolescents in Nairobi public secondary schools: association of percieved maladaptive parential behavior. African journal of psychiatry 15: 106-113.

22. Trickey D, Siddaway A, Meiser-Stedman R, Serpell L, Field A (2012) A meta-analysis of risk factors for posttraumatic stress disorder in children and adolescents. Clinical psychology review 32: 122-138.

23. Nakajima S, Ito M, Shirai A, Konishi T (2012) Complicated grief in those bereaved by violent death: the effects of post traumatic stress disorder on complicated grief. Dialogues Clin Neurosci 14: 210-214. 